\title{
Keratoconus Screening in Elementary School Children
}

\author{
Majid Moshirfar (D) - Madeline B. Heiland · David B. Rosen • \\ Yasmyne C. Ronquillo · Phillip C. Hoopes
}

Received: May 24, 2019 / Published online: July 18, 2019

(C) The Author(s) 2019
Keywords: Atopy; Collagen cross-linking; Keratoconus screening; Pediatrics; Subclinical keratoconus

Keratoconus is a chronic progressive degenerative structural disease of the cornea that leads to ectasia [1]. Recently the U.S. Food and Drug Administration approved collagen cross-linking (CCL), a nonsurgical intervention that improves the tensile strength of collagen by promoting fibrillin bonds, for the treatment of progressive keratoconus [2]. CCL has been available in Europe for nearly 10 years and has been shown to be a safe and effective treatment [3]. Long-term studies in pediatrics have shown CCL to be optimal and most disease-stabilizing when performed early in the course of the disease $[4,5]$. The disease course is more aggresive in children than in adults, and children are more likely to have advanced disease at presentation (Krumeich's classification grades: 1-4) $[1,4,6-8]$. Keratoconus in a child may be prone to oversight, as it rarely causes amblyopia; however, it has been reported in children as young as 4 years $[9,10]$. In agreement with the ideals of Corneal Ectasia Preferred Practice Pattern and the Pediatric Eye Evaluations Preferred Practice Pattern of the American Academy of Ophthalmology, we recommend early screening and treatment in pediatric patients due to poor visual outcomes of unmanaged keratoconus and the known disease course $[11,12]$. 
This article is based on previously conducted studies and does not contain any studies with human participants or animals performed by any of the authors.

The prevalence of keratoconus in adults is reported to be 1 in 2000 (0.05\%), although many experts belief the true incidence is higher [1]. In the pediatric population (age $0-17$ years), the prevalence of keratoconus is reported to be $0.16 \%$ based on the Intelligence Research in Sight Registry (IRIS) of the American Academy of Ophthalmology [13]. Incidence is likely influenced by environmental and geographic factors, such as high altitude and UV light exposure, suggesting that particular individuals exposed to these factors warrant extra care in screening programs $[14,15]$. Some ethnicities are affected more than others, with studies finding a higher incidence and often an earlier disease onset among people in Asia and the Middle East [16-18]. A pediatric study (age of study participants 6-21 years) in Saudi Arabia showed the incidence of keratoconus to be $4.79 \%$, which is significantly higher than the worldwide incidence in adults [19]. Additionally, a UK study showed 4.4-fold higher increased incidence in Asian individuals (India, Pakistan, Bangladesh) compared to the overall population incidence [20]. The higher incidence found in these populations suggests the role of both geography and genetics in the predisposition to keratoconus.

Currently, children undergo visual acuity testing at school under the guidance of The National Center for Children's Vision and Eye Health and the National Association of School Nurses [21]. However, subclinical keratoconus in a child may not be detected with visual acuity screening alone [22]. Commonly used topographic instruments are able to distinguish reliably between normal corneal topography and subclinical keratoconus [23]. As an example of a current organizational model for screening, the Light for Sight Foundation based in Switzerland conducts free keratoconus screening for all ages [24]. We propose that keratoconus screening using corneal imaging become a standard of practice in elementary schools.

Children with subclinical keratoconus and atopic diseases, such as pediatric asthma, hay fever, and atopic dermatitis (who are prone to ocular allergy and subsequent keratoconus), would particularly benefit from a screening program [10, 23, 25]. Atopic pediatric patients commonly manifest with allergic conjunctivitis, atopic keratoconjunctivitis, and vernal conjunctivitis, which are risk factors for chronic corneal inflammation, neovascularization, and epithelial injury $[10,25]$. These patients are at risk for keratoconus secondary to constant irritation and eye rubbing, which may result in the release of cytokines and apoptosis of keratocytes in addition to mechanical trauma to the cornea $[25,26]$. These patients can experience acute corneal hydrops secondary to rupture of Descemet's membrane [10, 27]. Therefore, avoidance of eye rubbing and vigilance in the management of seasonal allergies are crucial. We would like to suggest that the National Keratoconus Foundation (NKCF), perhaps in conjunction with Children's Eye Health and Safety Awareness month in August, could use their platform to raise awareness of the dangers of eye rubbing via school outreach programs $[28,29]$.

While placido-based topography using, for example, such systems such as the Humphrey Atlas 995 Topographer (Carl Zeiss AG, Oberkochen, Germany) and the TMS-4 Corneal Topographer (Tomey USA, Phoenix, AZ, USA) are validated options in keratoconus screening, we would like to examine cost-effective platforms for screening in schools. The cost of corneal topographers varies depending on the model (range $<\$ 10,000$ to $>\$ 40,000$ ). However, the cost of the device should not be a prohibitive factor to the availability of screening. There are promising new technologies that are affordable which could aid in screening. One device screens for keratoconus using software on a smartphone camera [30]. This device is affordable and requires no extra equipment, thereby enabling eye specialists to evaluate high-risk cases further. However, subclinical cases could be missed due to the lower sensitivity of this device [30]. Other technologies use input from a traditional corneal topographer to process data; these have a very high sensitivity (>99\%) [31]. Corneal topography measurements on both of these two devices can be 
completed by school nurses without the need for optometric training. While a full economic analysis is beyond the scope of this paper, utilizing cost-effective technologies that do not require highly trained technicians will allow for the implementation of keratoconus screening in elementary schools. We would also like to recognize that tomography using instruments such as the Galilei (Ziemer Ophthalmic Systems, Port, Switzerland) system and OCULUS Pentacam (OCULUS Optikgeräte $\mathrm{GmbH}$, Wetzlar, Germany), which allow for both anterior and posterior measurements of the cornea, may be a superior method for fully evaluating keratoconus after the initial screening is complete.

\section{CONCLUSION}

In summary, current visual acuity screening practices do not reflect the significance of keratoconus in the pediatric population or the educational, health, and social implications of visual loss in this population. We must consider the benefits of corneal topographic screening in elementary schools. At a minimum, children living in areas of high elevation and/or high UV exposure, children with atopy, and children living in geographic areas with a high incidence of keratoconus should be screened. Early detection and disease stabilization will be possible through mass screening of keratoconus in the pediatric population.

\section{ACKNOWLEDGEMENTS}

Funding. Research to Prevent Blindness provided funding for the Rapid Service Fees.

Authorship. All named authors meet the International Committee of Medical Journal Editors (ICMJE) criteria for authorship for this article, take responsibility for the integrity of the work as a whole, and have given their approval for this version to be published.
Disclosure. Majid Moshirfar, Madeline B. Heiland, David B. Rosen, Yasmyne C. Ronquillo and Phillip C. Hoopes have nothing to declare.

Compliance with Ethics Guidelines. This article is based on previously conducted studies and does not contain any studies with human participants or animals performed by any of the authors.

Open Access. This article is distributed under the terms of the Creative Commons Attribution-NonCommercial 4.0 International License (http://creativecommons.org/licenses/ by-nc/4.0/), which permits any noncommercial use, distribution, and reproduction in any medium, provided you give appropriate credit to the original author(s) and the source, provide a link to the Creative Commons license, and indicate if changes were made.

\section{REFERENCES}

1. Mukhtar S, Ambati BK. Pediatric keratoconus: a review of the literature. Int Ophthalmol. 2018;38(5):2257-66. https://doi.org/10.1007/s10792017-0699-8.

2. Belin MW, Lim L, Rajpal RK, Hafezi F, Gomes JAP, Cochener B. Corneal cross-linking. Cornea. 2018;37(10):1218-25. https://doi.org/10.1097/ICO. 0000000000001707 .

3. Avedro. Avedro receives CE mark for accelerated corneal cross-linking system. https://www.healio. com/ophthalmology/ophthalmic-business/news/ online/\%7B7e2fb7c2-f3ee-4347-becf-3a9997750461 $\% 7 \mathrm{D} /$ avedro-receives-ce-mark-for-accelerated-corn eal-cross-linking-system. Accessed 16 May 2019.

4. Godefrooij DA, Soeters N, Imhof SM, Wisse RPL. Corneal cross-linking for pediatric keratoconus: long-term results. Cornea. 2016;35(7):954-8. https://doi.org/10.1097/ICO.0000000000000819.

5. Sarac O, Caglayan M, Uysal BS, Uzel AGT, Tanriverdi B, Cagil N. Accelerated versus standard corneal collagen cross-linking in pediatric keratoconus patients: 24 months follow-up results. Contact Lens Anter Eye. 2018;41(5):442-7. https://doi.org/10. 1016/j.clae.2018.06.001.

6. Naderan M, Rajabi MT, Zarrinbakhsh P, Farjadnia $\mathrm{M}$. Is keratoconus more severe in pediatric 
population? Int Ophthalmol. 2017;37(5):1169-73. https://doi.org/10.1007/s10792-016-0382-5.

7. Léoni-Mesplié S, Mortemousque B, Touboul D, et al. Scalability and severity of keratoconus in children. Am J Ophthalmol. 2012;154(1):56-62.e1. https:// doi.org/10.1016/J.AJO.2012.01.025.

8. Chatzis N, Hafezi F. Progression of keratoconus and efficacy of corneal collagen cross-linking in children and adolescents. J Refract Surg. 2012;28(11):753-8. https://doi.org/10.3928/1081597X-20121011-01.

9. Sabti S, Tappeiner C, Frueh BE. Corneal cross-linking in a 4-year-old child with keratoconus and down syndrome. 2015;34(9):1157-60.

10. The necessity for ocular assessment in atopic children: bilateral corneal hydrops in an 8 year old (abstract). 2014. https://doi.org/10.1542/peds.20133750 .

11. Garcia-Ferrer FJ, Akpek EK, Amescua G, et al. Corneal Ectasia Preferred Practice Pattern ${ }^{\circledR}$. Ophthalmology. 2019;126(1):P170-215. https://doi.org/10. 1016/j.ophtha.2018.10.021.

12. Wallace MPH, Morse CL, Melia SCMM, et al. Pediatric Eye Evaluations Preferred Practice Pattern ${ }^{\circledR}$ : I. Vision screening in the primary care and community setting; II. Compr Ophthalmic Exam. 2018;125(1):P184-227. https://doi.org/10.1016/j. ophtha.2017.09.032.

13. Vision and Eye Health Surveillance System (VEHSS) Explore by Indicator | DDT | CDC. https://nccd.cdc. gov/DDT_VEHSS/LP?DataSourceTypeId=EHR\&Data SourceId=IRIS\&TopicId=TDX\&CategoryId=CDXC1 6\&IndicatorId=QDXDC16\&ShowFootnotes=true\& View=Map\&CompareId=\&YearId=YR8\&ResponseId =R16_1\&AgeId=AGE017\&GenderId=GALL\&RaceId $=$ ALLRACE\&RiskFactorId=RFALL\&Risk. Accessed 22 May 2019.

14. Althomali TA, Al-Qurashi IM, Al-Thagafi SM, Mohammed A, Almalki M. Prevalence of keratoconus among patients seeking laser vision correction in Taif area of Saudi Arabia. Saudi J Ophthalmol. 2018;32(2):114-8. https://doi.org/10. 1016/j.sjopt.2017.11.003.

15. Cristina Kenney M, Brown DJ. The cascade hypothesis of keratoconus. Contact Lens Anter Eye. 2003;26(3):139-46. https://doi.org/10.1016/S13670484(03)00022-5.

16. Assiri AA, Yousuf BI, Quantock AJ, Murphy PJ. Incidence and severity of keratoconus in Asir province, Saudi Arabia. Br J Ophthalmol. 2005;89(11): 1403-6. https://doi.org/10.1136/BJO.2005.074955.
17. Xu L, Wang YX, Guo Y, You QS, Jonas JB, Beijing Eye Study Group. Prevalence and associations of steep cornea/keratoconus in Greater Beijing. The Beijing Eye Study. PLoS One. 2012;7(7):e39313. https://doi.org/10.1371/journal.pone.0039313.

18. Jonas JB, Nangia V, Matin A, Kulkarni M, Bhojwani $K$. Prevalence and associations of keratoconus in Rural Maharashtra in Central India: the Central India Eye and Medical Study. Am J Ophthalmol. 2009;148(5):760-5. https://doi.org/10.1016/J.AJO. 2009.06.024.

19. Netto T. Prevalence of keratoconus in paediatric patients in Riyadh, Saudi Arabia. Br J Ophthalmol. 2018;102:1436-41. https://doi.org/10.1136/ bjophthalmol-2017-311391.

20. Pearson AR, Soneji B, Sarvananthan N, SandfordSmith JH. Does ethnic origin influence the incidence or severity of keratoconus? Eye. 2000;14(4):625-8. https://doi.org/10.1038/eye.2000.154.

21. Nottingham Chaplin PK, Baldonado K, Hutchinson A, Moore B. Vision and eye health. NASN Sch Nurse. 2015;30(3):154-60. https://doi.org/10.1177/ $1942602 X 15581054$.

22. Riley M, Locke AB, Skye EP. Health maintenance in school-aged children: part I. History, physical examination, screening, and immunizations. Am Fam Physician. 2011;83(6):683-88.

23. Shetty R, Rao H, Khamar P, et al. Keratoconus screening indices and their diagnostic ability to distinguish normal from ectatic corneas. Am J Ophthalmol. 2017;181:140-8. https://doi.org/10. 1016/j.ajo.2017.06.031.

24. Light for Sight. Light for Sight Foundation conducts free screenings for keratoconus. https:// lightforsight.org/screening-at-the-expat-expo2017-dietikon/. Accessed 15 May 2019.

25. Abelson $\mathrm{MB}$, Granet D. Ocular allergy in pediatric practice. Curr Allergy Asthma Rep. 2006;6(4):306-11. https://link.springer.com/content/pdf/10.1007\%2Fs 11882-006-0064-x.pdf.

26. Kim W-J, Rabinowitz YS, Meisler DM, Wilson SE. Keratocyte apoptosis associated with keratoconus. Exp Eye Res. 1999;69(5):475-81. https://doi.org/10. 1006/exer.1999.0719.

27. Slim EA, Jarade EF, Charanek BM, et al. Acute corneal hydrops mimicking infectious keratitis as initial presentation of keratoconus in a 10-year-old child. Case Rep Ophthalmol Med. 2015;2015: 308348. https://doi.org/10.1155/2015/308348. 
28. Prevent Blindness. Children's eye health and safety. https://www.preventblindness.org/childrens-eyehealth-safety. Accessed 23 May 2019.

29. National Keratoconus Foundation. https://www. nkcf.org/. Accessed 23 May 2019.

30. Askarian B, Chong JW, Tabei F, Askarian A. An affordable and easy-to-use diagnostic method for keratoconus detection using a smartphone. In:
Mori K, Petrick N, editors. Medical imaging 2018: computer-aided diagnosis, vol. 10575. Bellingham: SPIE; 2018. p. 37. https://doi.org/10.1117/12. 2293765.

31. Lavric A, Valentin P. KeratoDetect: keratoconus detection algorithm using convolutional neural networks. Comput Intell Neurosci. 2019;2019:1-9. https://doi.org/10.1155/2019/8162567. 